\title{
Microglial control of neuronal activity
}

\section{Catherine Béchade, Yasmine Cantaut-Belarif and Alain Bessis*}

Institut de Biologie, Ecole Normale Supérieure, Inserm U1025, CNRS UMR8197, Paris, France

Edited by:

Marie-Eve Tremblay, Université

Laval, Canada

Reviewed by:

Ania K. Majewska, University of

Rochester, USA

Rafael Linden, Federal University of

Rio de Janeiro, Brazil

Wai T. Wong, National Eye Institute, NIH, USA

Junichi Nabekura, National Instritute for Physiological Sciences, Japan

*Correspondence:

Alain Bessis, Ecole Normale

Supérieure, Institut de Biologie,

CNRS, UMR 8197, 46 rue d'UIm,

F-75005 Paris, France.

e-mail: alain.bessis@ens.fr
Fine-tuning of neuronal activity was thought to be a neuron-autonomous mechanism until the discovery that astrocytes are active players of synaptic transmission. The involvement of astrocytes has changed our understanding of the roles of non-neuronal cells and shed new light on the regulation of neuronal activity. Microglial cells are the macrophages of the brain and they have been mostly investigated as immune cells. However, recent data discussed in this review support the notion that, similarly to astrocytes, microglia are involved in the regulation of neuronal activity. For instance, in most, if not all, brain pathologies a strong temporal correlation has long been known to exist between the pathological activation of microglia and dysfunction of neuronal activity. Recent studies have convincingly shown that alteration of microglial function is responsible for pathological neuronal activity. This causal relationship has also been demonstrated in mice bearing loss-of-function mutations in genes specifically expressed by microglia. In addition to these long-term regulations of neuronal activity, recent data show that microglia can also rapidly regulate neuronal activity, thereby acting as partners of neurotransmission.

Keywords: microglia, neurotransmission, inflammation, synapse, glial cells

\section{INTRODUCTION}

Microglial cells are one of the glial cell populations of the brain. In contrast to other glial cell types such as oligodendrocytes or astrocytes, the role of microglia in the regulation of neuronal activity has been somewhat overlooked. Microglia are macrophages of the nervous tissue and as immune cells they can detect and react to infection, trauma, ischemia, degeneration, or any alterations in brain homeostasis. Actually, most brain pathologies, if not all, are associated with early microglial activation ${ }^{1}$. Thus, microglial activation was demonstrated based on histopathological data, in vivo brain imaging or cytokine expression upon axotomy (Blinzinger and Kreutzberg, 1968), during degenerative (Haga et al., 1989; Cagnin et al., 2001; reviewed in Cameron and Landreth, 2010) or neuropsychiatric diseases (review in Beumer et al., 2012). Of note, the above-described disorders are also associated with early synaptic dysfunction (Blinzinger and Kreutzberg, 1968; references in Selkoe, 2002; Penzes et al., 2011; Peça and Feng, 2012). Such a temporal correlation between microglial activation and synaptic dysfunction during brain pathologies suggests that regulatory interactions exist between the activation of microglia and neurotransmission. In addition, the functional properties of microglia are compatible with an involvement in the control of neuronal activity. They express receptors for most neurotransmitters

\footnotetext{
${ }^{1}$ The notion of "activation" of microglia is quite a loosely-defined concept adapted from the well-defined concept of macrophage activation (Taylor et al., 2005; Perry et al., 2007). Activation is associated with pathology but is often used to describe the consequences of any stimulation of microglia. Because different stimulation can induce different responses in microglia, there is not one single parameter that characterizes an "activation." Therefore, various parameters have been used to establish microglial "activation" such as changes in density, morphology, or expression of proteins. Whenever possible, we have used the notion of stimulation instead of activation and described the nature of the stimuli.
}

(Kettenmann et al., 2011; Kaindl et al., 2012) and produce a large repertoire of molecules known to modulate neuronal activity and plasticity. In addition, microglia are highly ramified cells and their ramifications rapidly scan the local environment and react to its modification (Davalos et al., 2005). Finally, microglial processes physically contact synaptic elements (Wake et al., 2009; Tremblay et al., 2010; see also Schafer et al., 2012), allowing for an accurate control of synaptic function.

In this review, we will highlight recent studies suggesting or demonstrating the involvement of microglia in the control of neuronal activity. Firstly, we will describe how microglial dysfunction is primarily responsible for the alterations in neuronal activity under pathological situations. We will then show that in the healthy brain microglia can be described as partners of neurotransmission.

\section{MICROGLIA DYSFUNCTION PERTURBS NEURONAL ACTIVITY}

Microglia were initially described as sensors of pathological events (Kreutzberg, 1996). It is now widely accepted that microglia are not only sensors but also active players of pathological states in the brain. Understanding the consequences of microglial dysfunction on neuronal phenotype is important to understand the etiology of the disease state and to propose therapeutic strategies. In this first section we will review studies in which microglia are the primary cause of alterations in neuronal activity during non-physiological states. Importantly, the information gathered from pathological situations is relevant for the understanding microglial function in the absence of pathology, as will be discussed in the second section of this review.

Analyses of mice bearing loss-of-function mutations in genes involved in microglia-specific pathways exemplify the link between microglial dysfunction and neuronal activity. CX3CR1 is 
the microglial receptor for the neuronal chemokine fractalkine (CX3CL1). This complementary expression of ligand and receptor on neurons and microglia respectively, suggests that their interaction may play a role in modulating neurotransmission. Mice with a CX3CR1 loss-of-function mutation exhibit an impairment of hippocampal long-term potentiation (LTP) as well as cognitive deficits (Rogers et al., 2011). The CX3CL1/R1 signaling pathway also appears to be involved in synaptic maturation since CX3CR1 deficiency leads to a delay in the maturation of glutamatergic thalamocortical synapses, as well as a transient immature connectivity in the developing hippocampus (Paolicelli et al., 2011; Hoshiko et al., 2012). Of note, these latter alterations might be secondary to a decreased recruitment of microglia and not to a direct involvement of CX3CR1 signaling in the regulation of neurotransmission (Paolicelli et al., 2011; Hoshiko et al., 2012). Another example of a neuronal-microglial interaction is provided by the analysis of CD200-deficient mice. CD200R is a membrane protein exclusively expressed by microglia. Its ligand, CD200 is expressed by neurons, oligodendrocytes and astrocytes (Costello et al., 2011). It was demonstrated that LTP is inhibited in CD200-deficient mice, further supporting the notion that the integrity of microglial signaling is crucial for neurotransmission homeostasis (Costello et al., 2011). Finally, synaptic alterations have also been demonstrated upon the loss-of-function mutation of DAP12, a transmembrane protein associated with various lymphoid and myeloid receptors such as TREM2 (Tomasello et al., 2000). In the brain, DAP12 and TREM2 are exclusively expressed by microglia and DAP12 loss-of-function results in an enhanced hippocampal LTP and major changes in glutamatergic transmission (Roumier et al., 2004, 2008). As for CX3CR1and CD200-deficient mice, the molecular mechanisms linking microglial deficiency to synaptic alterations in DAP12KO mice are not known. Interestingly however, the DAP12-mutant mouse is a model for Nasu-Hakola disease in which patients display progressive presenile dementia associated with bone cysts (Hakola, 1972), together with leukodystrophy and astrogliosis in the brain (Satoh et al., 2011). Nasu-Hakola disease is caused by mutations in the genes encoding microglial DAP12 or TREM2 (Paloneva et al., 2000), and because of this restricted expression, it has been described as the first microgliopathy (Bianchin et al., 2010). Thus, dysfunction of DAP12 signaling, which is exclusively expressed by microglia impacts synaptic transmission (Roumier et al., 2004), mouse behavior (Kaifu et al., 2003), and higher brain functions in human (Paloneva et al., 2000).

A link between microglia and higher brain function has also been proposed in the case of the mouse model of obsessivecompulsive disorder. Disruption of the Hoxb8 gene, expressed by a subpopulation of microglia, caused mice to groom compulsively (Chen et al., 2010; see however Holstege et al., 2008). Transplantation of wild type bone-marrow cells into Hoxb8 mutant mice rescued the phenotype (Chen et al., 2010) leading to the hypothesis that the pathological grooming behavior observed in Hoxb8 mutant mice may result from deficient mutant microglia.

Rett syndrome is another example of microglial involvement in psychiatric disease. Rett syndrome is an autism spectrum disorder caused by mutations in the gene encoding the methyl CpG binding protein-2 (MeCP2). Rett syndrome patients exhibit dendritic and synaptic abnormalities in selected regions (references in Chahrour and Zoghbi, 2007). MeCP2 deficient mice mimic the human syndrome (Chen et al., 2001; Guy et al., 2001; Shahbazian et al., 2002). Transplantation of wild type bone marrow into irradiated MeCP2-null hosts was recently shown to lead to engraftment of MeCP2-expressing microglia in the brain parenchyma and to a rescue of the brain phenotype (Derecki et al., 2012). Involvement of microglia in Rett syndrome is strengthened by in vitro observations showing that $\mathrm{MeCP} 2$-null microglia release high levels of glutamate, which induced changes in dendritic morphology and a reduced number of postsynaptic densities (Maezawa and Jin, 2010). Thus, microglia have an active role in this disorder by a mechanism that remains to be described.

These examples of psychiatric phenotypes induced primarily by deficiencies of microglial function support the notion that microglia can actively modulate neuronal functions, including learning and memory (Blank and Prinz, 2013). Yet, it cannot be excluded that microglial dysfunctions induce a general change of brain homeostasis resulting in non-specific defects in neuronal activity. However, in some instances, such as chronic pain, it could be shown that pathological effects on neuronal activity are due a deregulation of local microglial mechanisms that might be dedicated to the control of neurotransmission. For instance, stimulation of microglial $\mathrm{P} 2 \mathrm{X} 4$ receptors induces the release of pain mediators such as PGE2 (Ulmann et al., 2010) or BDNF (Coull et al., 2005) and is necessary for the induction of allodynia after nerve injury (Tsuda et al., 2003). In addition, upon neuropathic pain, the dorsal horn microglia produces BDNF, which stimulates the neuronal TrkB receptor and induces a shift in the chloride gradient in nociceptive neurons (Coull et al., 2005). Such shift increases the excitability of the neurons through $\mathrm{GABA}_{\mathrm{A}}$ receptor-mediated depolarization (Coull et al., 2003).

These examples show that local and specific interactions between microglia and neurons can be responsible for the altered neuronal activity observed in pathology. However, microglia and neurons functionally interact in healthy conditions (Tremblay et al., 2011) as well, and several studies have now established that microglia can rapidly modulate neuronal activity in basal conditions.

\section{MICROGLIA AS GENUINE PARTNERS OF SYNAPTIC ACTIVITY}

Under physiological conditions, microglia react rapidly to neuronal activity by modulating the physical contacts that their numerous processes continuously establish with synaptic elements (Wake et al., 2009; Tremblay et al., 2010). Microglia are thus potentially accurate sensors of neuronal activity and a reciprocal control of neurotransmission by microglia can be expected. The ability of microglia to rapidly modulate synaptic activity was initially exemplified by treating cultured neurons or acute brain slices with medium conditioned by cultured microglia. Microglia conditioned-medium was shown to increase both the amplitude and duration of the NMDA-receptor induced currents (Moriguchi et al., 2003; Hayashi et al., 2006). The nature of the signaling molecules involved in this process is still unknown and were proposed to be a secreted protein(s) (Moriguchi et al., 2003) 
or glycine (Hayashi et al., 2006). In fact, microglia produce a broad spectrum of signaling molecules known to regulate synaptic function, including cytokines (Elkabes et al., 1996; Hanisch, 2002), neurotransmitters (Piani and Fontana, 1994; Hayashi et al., 2006; Flierl et al., 2007; Pascual et al., 2012), and extracellular matrix proteins (Chamak et al., 1994). A direct regulation of synaptic properties by microglia is therefore expected. Amongst the microglial molecules with a putative role in neurotransmission, TNF $\alpha$ deserves specific attention. This cytokine was shown to control basal synaptic functions (Santello et al., 2011) as well as plasticity (Stellwagen and Malenka, 2006; Kaneko et al., 2008; Costello et al., 2011; Santello et al., 2011), and this role was attributed to TNF $\alpha$ produced by astrocytes (Stellwagen and Malenka, 2006). However, the astrocytes have often been thought to express TNF $\alpha$ because cultures of astrocytes are consistently contaminated by microglia (Saura, 2007; Barres, 2008). In addition, the transcriptome analysis from purified astrocytes reveals no TNF $\alpha$-encoding transcript in astrocytes (Sharma et al., 2007; Cahoy et al., 2008; Doyle et al., 2008; Meissner et al., 2008; Foo et al., 2011; Zamanian et al., 2012). Thus, the TNF $\alpha$ that controls several aspects of synaptic transmission might, in fact, be produced by microglial cells, but this has not yet been firmly established.

It has also been shown that microglia can shed microvesicles a few seconds after ATP stimulation, most probably by a P2X7-dependent mechanism (Bianco et al., 2005). When these vesicles were harvested from cultured microglia and applied to cultured hippocampal neurons, they induced an increased frequency of miniature excitatory post-synaptic currents (mEPSC), supposedly through presynaptic regulation (Antonucci et al., 2012). Analysis of the regulatory pathway between microglia and synaptic activity led the authors to propose that microglial micro-vesicles regulate mEPSCs through a phosphatydil-dependent regulation of presynaptic vesicle release (Antonucci et al., 2012). The functional relevance and specificity of this mechanism remains to be established but it raises the provocative hypothesis that physical contacts, or membrane exchange between microglia and neurons, could actively and rapidly regulate neurotransmission.

The above-described studies suggest, but do not demonstrate, that microglia can rapidly modulate synaptic function. Several studies have specifically stimulated microglia and analyzed the consequences on neuronal activity in a similar way to what was done to investigate the role of astrocytes in neurotransmission. Application of fractalkine onto neuron cultures was shown to induce a strong and rapid modulation of calcium currents in neurons (Meucci et al., 1998). Such modulation was actually the first demonstration that stimulation of microglia could rapidly modulate the activity of neurons (although it was at first incorrectly attributed to a direct stimulation of neurons by fractalkine). This modulation has also been confirmed in acute hippocampal slices, in which stimulation of microglia by fractalkine induces a significant and transient reduction of the amplitude of evoked EPSCs in CA1 pyramidal neurons (Ragozzino et al., 2006; see Figure 1A). It was further demonstrated that this reduction involves adenosine, supposedly acting on neuronal A3R receptors (Piccinin et al., 2010). The probable mechanism of regulation is that fractalkine induces the microglial release of adenosine, which in turn inhibits the presynaptic release of glutamate (Figure 1A). Alternatively, microglia could produce ATP that is rapidly degraded into adenosine by ectonucleotidases. The involvement of other cell types such as astrocytes has not yet been ruled out.

An alternative rapid regulation of neuronal activity by microglia has recently been established upon application of lipo-polysaccharide (LPS_-Pascual et al., 2012; Figure 1A). LPS is a ligand of TLR4 that mimics bacterial infection and can reveal pathological pathways. TLR4 is exquisitely expressed by microglia and can also be stimulated by several endogenous ligands (Habich et al., 2005; Gondokaryono et al., 2007; Midwood et al., 2009; Milanski et al., 2009; references in Lucin and Wyss-Coray, 2009). Therefore, the mechanisms revealed by LPS application probably have a physiological relevance. Stimulation of microglia by addition of LPS onto acute hippocampal slices induces a rapid and transient increase in the frequency of spontaneous synaptic AMPAergic post-synaptic currents in CA1 neurons. This effect does not occur in slices prepared from Pu.1 deficient mice that lack microglia, showing that the effect of LPS requires microglia. It was then demonstrated that upon LPS stimulation, microglia rapidly produce ATP, which recruits astrocytes. Astrocytes subsequently release glutamate, and this leads to increased excitatory transmission via a metabotropic glutamate receptor-dependent mechanism (Pascual et al., 2012).

The above-described studies show that stimulation of microglia modulates neuronal activity in vitro. The occurrence of regulating interactions between microglia and neuronal activity has recently been demonstrated in vivo in the zebrafish larva (Li et al., 2012; Figure 1B). In this system, microglia monitor spontaneous or visually evoked neuronal activity, and send bulbous processes toward the most active neurons, as detected by their production of ATP. These contacts between microglial endings and active neurons induce a rapid decrease in both frequency and amplitude of neuronal calcium events (Li et al., 2012). This study confirms and extends the data obtained upon stimulation of microglia and further demonstrates that microglia are genuine partners of neuronal activity in the healthy brain.

\section{THE RIGHT TOOLS TO TARGET THE RIGHT CELLS}

The role of microglia in the regulation of neurotransmission is far less studied than that of astrocytes. This might be due to a lesser involvement of microglia in such regulation. Alternatively, this could also be due to the fact that the characterization of microglia as regulators of neurotransmission has been hindered by the lack of tools to specifically stimulate or block their function. Such tools are available for astrocytes and their function has been blocked by application of pharmacological inhibitors such as Fluoroacetate or calcium chelators (Henneberger et al., 2010). Stimulation of astrocytes has also been achieved, mechanically (see e.g., Liu et al., 2011) or by local application of synthetic agonists or local uncaging of calcium or glutamate (Pascual et al., 2005; Agulhon et al., 2010). Although the physiological relevance of such treatments is still debated (Hamilton and Attwell, 2010), 

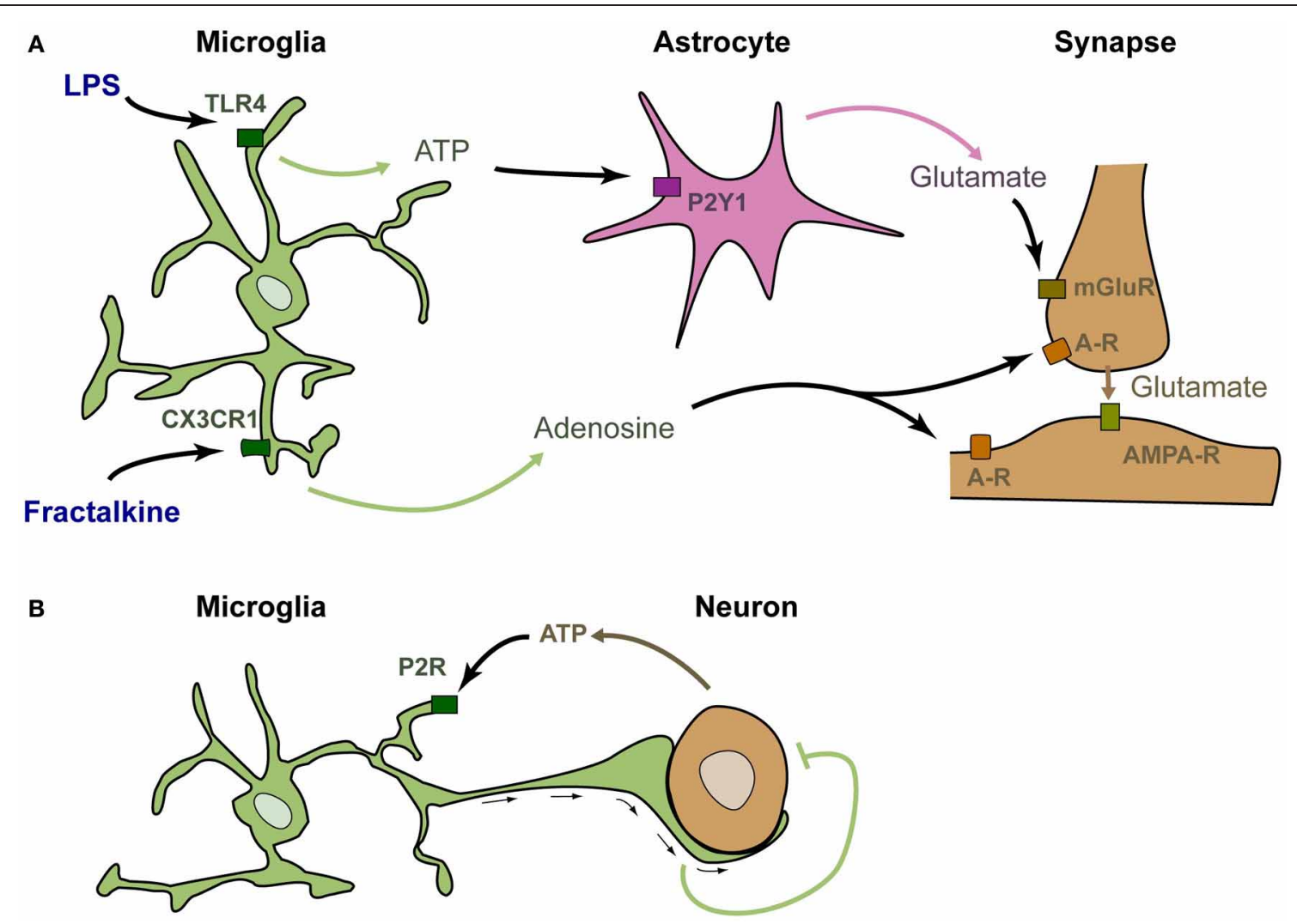

FIGURE 1 | Microglia are genuine partners of synaptic transmission. (A) In acute rodent brain slices, stimulation of microglia by LPS induces the rapid release of ATP, which recruits astrocytes. Upon purinergic stimulation, astrocytes release glutamate, inducing a mGluR-dependent release of presynaptic glutamate (Pascual et al., 2012). Stimulation of microglia by fractalkine induces the release of adenosine, which decreases neuronal activity (Meucci et al., 1998; Ragozzino et al., 2006; Piccinin et al., 2010). (B) In zebrafish larva, active neurons release the ATP that attracts microglial bulbous processes. These processes decrease neuronal activity by an as yet unknown mechanism (Li et al., 2012). these protocols allowed the characterization of astrocytes as regulators of the normal function and plasticity of neural circuits in vitro and in vivo. Comparable tools to tune the function of microglia are lacking, mostly because of a specificity issue. For instance, minocycline is known to block microglial function (Yrjänheikki et al., 1998), but its molecular and cellular targets remain unidentified and its specificity remains to be firmly established. Moreover, microglia can be stimulated by a large variety of inflammatory molecules such as cytokines or interleukins, but their receptors have also been detected on neurons and astrocytes, preventing accurate interpretation of their putative effects. In addition, as mentioned previously in relation to the cellular origin of $\mathrm{TNF} \alpha$, the consistent contamination of neuronal and astrocyte cultures by microglia has made it difficult to address the correct expression of microglial molecules. For instance, CX3CR1, the fractalkine receptor that was initially thought to be expressed by neurons (Meucci et al., 1998, 2000; Hughes et al., 2002; Ragozzino et al., 2006), is now demonstrated to be exclusively expressed by microglia (Cardona et al., 2006; Lauro et al., 2008). Similarly, TLR4, the LPS receptor, was mistakenly detected in astrocytic (Bowman et al., 2003; Alfonso-Loeches et al., 2010) and neuronal cultures (Tang et al., 2007). Indeed, when microglia were efficiently depleted from astrocyte cultures, TLR4 was no longer detected (Lehnardt et al., 2002; Pascual et al., 2012). In addition, expression of TLR4 has never been found in healthy neurons or astrocytes. Finally, data mining of Gene Expression Omnibus DNA array experiments performed on purified cells confirmed that TLR4 is exclusively expressed by microglia (Pascual et al., 2012). Thus, CX3CR1 and TLR4 expression is limited to microglia and, as described above, can be used to specifically stimulate these cells and study their involvement in biological processes. We speculate that the future development tools to specifically block microglial function will also be instrumental to understand the involvement of these cells in wide variety of physiological processes.

\section{CONCLUSION}

The biological relevance of microglia as active sensors of brain parenchyma was until recently, principally recognized in pathological tissues. The role of microglia in the healthy brain is now acknowledged (Graeber, 2010; PontLezica et al., 2011; Tremblay et al., 2011). Here we have reviewed studies indicating that microglia are able to control neuronal activity, from synaptic transmission to higher brain functions. Microglia have often been described as 
"good" or "bad" cells (Kempermann and Neumann, 2003; Kettenmann, 2007; Watkins et al., 2007; Aguzzi et al., 2013). Considering microglia as partners of neuronal function will certainly help to provide a more accurate and integrated understanding of their roles, beyond the primary "beneficial vs. detrimental" dichotomy. It will also extend our understanding of non-cell autonomous regulation of neuronal activity and

\section{REFERENCES}

Agulhon, C., Fiacco, T. A., and McCarthy, K. D. (2010). Hippocampal short- and longterm plasticity are not modulated by astrocyte $\mathrm{Ca} 2+$ signaling. Science 327, 1250-1254.

Aguzzi, A., Barres, B. A., and Bennett, M. L. (2013). Microglia: scapegoat, saboteur, or something else? Science 339, 156-161.

Alfonso-Loeches, S., Pascual-Lucas, M., Blanco, A. M., Sanchez-Vera, I., and Guerri, C. (2010). Pivotal role of TLR4 receptors in alcoholinduced neuroinflammation and brain damage. J. Neurosci. 30, 8285-8295.

Antonucci, F., Turola, E., Riganti, L., Caleo, M., Gabrielli, M., Perrotta, C., et al. (2012). Microvesicles released from microglia stimulate synaptic activity via enhanced sphingolipid metabolism. EMBO J. 31, 1231-1240.

Barres, B. A. (2008). The mystery and magic of glia: a perspective on their roles in health and disease. Neuron $60,430-440$.

Beumer, W., Gibney, S. M., Drexhage, R. C., Pont-Lezica, L., Doorduin, J., Klein, H. C., et al. (2012). The immune theory of psychiatric diseases: a key role for activated microglia and circulating monocytes. J. Leukoc. Biol. 92, 959-975.

Bianchin, M. M., Martin, K. C., de Souza, A. C., de Oliveira, M. A., and Rieder, C. R. (2010). Nasu-Hakola disease and primary microglial dysfunction. Nat. Rev. Neurol. 6, 2 p following 523 .

Bianco, F., Pravettoni, E., Colombo, A., Schenk, U., Möller, T., Matteoli, M., et al. (2005). Astrocyte-derived ATP induces vesicle shedding and IL-1 beta release from microglia. J. Immunol. 174, 7268-7277.

Blank, T., and Prinz, M. (2013). Microglia as modulators of cognition and neuropsychiatric disorders. Glia 61, 62-70.

Blinzinger, K., and Kreutzberg, G. (1968). Displacement of synaptic terminals from regenerating motoneurons by microglial cells. Z. Zellforsch. Mikrosk. Anat. 85, 145-157.
Bowman, C. C., Rasley, A., Tranguch, S. L., and Marriott, I. (2003). Cultured astrocytes express toll-like receptors for bacterial products. Glia 43, 281-291.

Cagnin, A., Brooks, D. J., Kennedy, A. M., Gunn, R. N., Myers, R., Turkheimer, F. E., et al. (2001). In-vivo measurement of activated microglia in dementia. Lancet 358, 461-467.

Cahoy, J. D., Emery, B., Kaushal, A., Foo, L. C., Zamanian, J. L., Christopherson, K. S., et al. (2008). A transcriptome database for astrocytes, neurons, and oligodendrocytes: a new resource for understanding brain development and function. J. Neurosci. 28, 264-278.

Cameron, B., and Landreth, G. E. (2010). Inflammation, microglia, and Alzheimer's disease. Neurobiol. Dis. 37, 503-509.

Cardona, A. E., Pioro, E. P., Sasse, M. E., Kostenko, V., Cardona, S. M., Dijkstra, I. M., et al. (2006). Control of microglial neurotoxicity by the fractalkine receptor. Nat. Neurosci. 9, 917-924.

Chahrour, M., and Zoghbi, H. Y. (2007). The story of Rett syndrome: from clinic to neurobiology. Neuron $56,422-437$.

Chamak, B., Morandi, V., and Mallat, M. (1994). Brain macrophages stimulate neurite growth and regeneration by secreting thrombospondin. J. Neurosci. Res. 38, 221-233.

Chen, R. Z., Akbarian, S., Tudor, M., and Jaenisch, R. (2001). Deficiency of methyl-CpG binding protein-2 in CNS neurons results in a Rett-like phenotype in mice. Nat. Genet. 27, 327-331.

Chen, S.-K., Tvrdik, P., Peden, E., Cho, S., Wu, S., Spangrude, G., et al. (2010). Hematopoietic origin of pathological grooming in Hoxb8 mutant mice. Cell 141, 775-785.

Costello, D. A., Lyons, A., Denieffe, S., Browne, T. C., Cox, F. F., and Lynch, M. A. (2011). Long term potentiation is impaired in membrane glycoprotein CD200-deficient mice: a role for Toll-like receptor activation. J. Biol. Chem. 286, 34722-34732.

Coull, J. A. M., Beggs, S., Boudreau, D., Boivin, D., Tsuda, M., Inoue, K.,

shed new light on the role of microglia in the pathological brain.

\section{ACKNOWLEDGMENTS}

We gratefully thank Lorena Pont-Lezica for critical reading of the manuscript. The work of our laboratory is supported by a grant from the 7th Framework Program Moodinflame (222963).

et al. (2005). BDNF from microglia causes the shift in neuronal anion gradient underlying neuropathic pain. Nature 438, 1017-1021.

Coull, J. A. M., Boudreau, D., Bachand, K., Prescott, S. A., Nault, F., Sík, A., et al. (2003). Trans-synaptic shift in anion gradient in spinal lamina I neurons as a mechanism of neuropathic pain. Nature 424, 938-942.

Davalos, D., Grutzendler, J., Yang, G., Kim, J. V., Zuo, Y., Jung, S., et al. (2005). ATP mediates rapid microglial response to local brain injury in vivo. Nat. Neurosci. 8, 752-758.

Derecki, N. C., Cronk, J. C., Lu, Z., Xu, E., Abbott, S. B. G., Guyenet, P. G., et al. (2012). Wild-type microglia arrest pathology in a mouse model of Rett syndrome. Nature 484, 105-109.

Doyle, J. P., Dougherty, J. D., Heiman, M., Schmidt, E. F., Stevens, T. R., Ma, G., et al. (2008). Application of a translational profiling approach for the comparative analysis of CNS cell types. Cell 135, 749-762.

Elkabes, S., DiCicco-Bloom, E. M., and Black, I. B. (1996). Brain microglia/macrophages express neurotrophins that selectively regulate microglial proliferation and function. J. Neurosci. 16, 2508-2521.

Flierl, M. A., Rittirsch, D., Nadeau, B. A., Chen, A. J., Sarma, J. V., Zetoune, F. S., et al. (2007). Phagocyte-derived catecholamines enhance acute inflammatory injury. Nature 449, 721-725.

Foo, L. C., Allen, N. J., Bushong, E. A., Ventura, P. B., Chung, W.-S., Zhou, L., et al. (2011). Development of a method for the purification and culture of rodent astrocytes. Neuron 71 , 799-811.

Gondokaryono, S. P., Ushio, H., Niyonsaba, F., Hara, M., Takenaka, H., Jayawardana, S. T. M., et al. (2007). The extra domain A of fibronectin stimulates murine mast cells via toll-like receptor 4 . J. Leukoc. Biol. 82, 657-665.

Graeber, M. B. (2010). Changing face of microglia. Science 330, 783-788.

Guy, J., Hendrich, B., Holmes, M., Martin, J. E., and Bird, A. (2001).
A mouse Mecp2-null mutation causes neurological symptoms that mimic Rett syndrome. Nat. Genet. 27, 322-326.

Habich, C., Kempe, K., van der Zee, R., Rümenapf, R., Akiyama, H., Kolb, H., et al. (2005). Heat shock protein 60: specific binding of lipopolysaccharide. J. Immunol. 174, 1298-1305.

Haga, S., Akai, K., and Ishii, T. (1989). Demonstration of microglial cells in and around senile (neuritic) plaques in the Alzheimer brain. An immunohistochemical study using a novel monoclonal antibody. Acta Neuropathol. 77, 569-575.

Hakola, H. P. (1972). Neuropsychiatric and genetic aspects of a new hereditary disease characterized by progressive dementia and lipomembranous polycystic osteodysplasia. Acta Psychiatr. Scand. Suppl. 232, 1-173.

Hamilton, N. B., and Attwell, D. (2010). Do astrocytes really exocytose neurotransmitters? Nat. Rev. Neurosci. 11, 227-238.

Hanisch, U.-K. (2002). Microglia as a source and target of cytokines. Glia 40, 140-155.

Hayashi, Y., Ishibashi, H., Hashimoto, K., and Nakanishi, H. (2006). Potentiation of the NMDA receptormediated responses through the activation of the glycine site by microglia secreting soluble factors. Glia 53, 660-668.

Henneberger, C., Papouin, T., Oliet, S. H. R., and Rusakov, D. A. (2010). Long-term potentiation depends on release of D-serine from astrocytes. Nature 463, 232-236.

Holstege, J. C., De Graaff, W., Hossaini, M., Cardona Cano, S., Jaarsma, D. Van den Akker, E., et al. (2008). Loss of Hoxb8 alters spinal dorsal laminae and sensory responses in mice. Proc. Natl. Acad. Sci. U.S.A. 105, 6338-6343.

Hoshiko, M., Arnoux, I., Avignone, E., Yamamoto, N., and Audinat, E. (2012). Deficiency of the microglial receptor CX3CR1 impairs postnatal functional development of thalamocortical synapses in the barrel cortex. J. Neurosci. 32, 15106-15111. 
Hughes, P. M., Botham, M. S., Frentzel, S., Mir, A., and Perry, V. H. (2002). Expression of fractalkine (CX3CL1) and its receptor, CX3CR1, during acute and chronic inflammation in the rodent CNS. Glia 37, 314-327.

Kaifu, T., Nakahara, J., Inui, M., Mishima, K., Momiyama, T., Kaji, M., et al. (2003). Osteopetrosis and thalamic hypomyelinosis with synaptic degeneration in DAP12deficient mice. J. Clin. Invest. 111, 323-332.

Kaindl, A. M., Degos, V., Peineau, S., Gouadon, E., Chhor, V., Loron, G., et al. (2012). Activation of microglial N-methyl-D-aspartate receptors triggers inflammation and neuronal cell death in the developing and mature brain. Ann. Neurol. 72, 536-549.

Kaneko, M., Stellwagen, D., Malenka, R. C., and Stryker, M. P. (2008). Tumor necrosis factor-alpha mediates one component of competitive, experience-dependent plasticity in developing visual cortex. Neuron $58,673-680$

Kempermann, G., and Neumann, H. (2003). Neuroscience. Microglia: the enemy within? Science 302, 1689-1690.

Kettenmann, H. (2007). Neuroscience: the brain's garbage men. Nature 446 , 987-989.

Kettenmann, H., Hanisch, U.-K., Noda, M., and Verkhratsky, A. (2011). Physiology of microglia. Physiol. Rev. 91, 461-553.

Kreutzberg, G. W. (1996). Microglia: a sensor for pathological events in the CNS. Trends Neurosci. 19, 312-318.

Lauro, C., Angelantonio, S. D., Cipriani, R., Sobrero, F., Antonilli, L., Brusadin, V., et al. (2008). Activity of adenosine receptors type 1 Is required for CX3CL1-mediated neuroprotection and neuromodulation in hippocampal neurons. J. Immunol. 180, 7590-7596.

Lehnardt, S., Lachance, C., Patrizi, S., Lefebvre, S., Follett, P. L., Jensen, F. E., et al. (2002). The toll-like receptor TLR4 is necessary for lipopolysaccharide-induced oligodendrocyte injury in the CNS. J. Neurosci. 22, 2478-2486.

Li, Y., Du, X.-F., Liu, C.-S., Wen, Z.-L., and Du, J.-L. (2012). Reciprocal regulation between resting microglial dynamics and neuronal activity in vivo. Dev. Cell 23, 1189-1202.

Liu, T., Sun, L., Xiong, Y., Shang, S., Guo, N., Teng, S., et al. (2011). Calcium triggers exocytosis from two types of organelles in a single astrocyte. J. Neurosci. 31, 10593-10601.
Lucin, K. M., and Wyss-Coray, T. (2009). Immune activation in brain aging and neurodegeneration: too much or too little? Neuron 64 110-122.

Maezawa, I., and Jin, L.-W. (2010). Rett syndrome microglia damage dendrites and synapses by the elevated release of glutamate. J. Neurosci. 30, 5346-5356.

Meissner, A., Mikkelsen, T. S., Gu, H., Wernig, M., Hanna, J., Sivachenko, A., et al. (2008). Genome-scale DNA methylation maps of pluripotent and differentiated cells. Nature 454, 766-770.

Meucci, O., Fatatis, A., Simen, A. A., Bushell, T. J., Gray, P. W., and Miller, R. J. (1998). Chemokines regulate hippocampal neuronal signaling and gp120 neurotoxicity. Proc. Natl. Acad. Sci. U.S.A. 95, 14500-14505.

Meucci, O., Fatatis, A., Simen, A. A., and Miller, R. J. (2000). Expression of CX3CR1 chemokine receptors on neurons and their role in neuronal survival. Proc. Natl. Acad. Sci. U.S.A. 97, 8075-8080.

Midwood, K., Sacre, S., Piccinini, A. M., Inglis, J., Trebaul, A., Chan, E., et al. (2009). Tenascin-C is an endogenous activator of Tolllike receptor 4 that is essential for maintaining inflammation in arthritic joint disease. Nat. Med. 15, 774-780.

Milanski, M., Degasperi, G., Coope, A., Morari, J., Denis, R., Cintra, D. E., et al. (2009). Saturated fatty acids produce an inflammatory response predominantly through the activation of TLR4 signaling in hypothalamus: implications for the pathogenesis of obesity. J. Neurosci. 29, 359-370.

Moriguchi, S., Mizoguchi, Y., Tomimatsu, Y., Hayashi, Y., Kadowaki, T., Kagamiishi, Y., et al. (2003). Potentiation of NMDA receptor-mediated synaptic responses by microglia. Brain Res. Mol. Brain Res. 119, 160-169.

Paloneva, J., Kestilä, M., Wu, J., Salminen, A., Böhling, T., Ruotsalainen, V., et al. (2000). Loss-of-function mutations in TYROBP (DAP12) result in a presenile dementia with bone cysts. Nat. Genet. 25, 357-361.

Paolicelli, R. C., Bolasco, G., Pagani, F., Maggi, L., Scianni, M., Panzanelli, P., et al. (2011). Synaptic pruning by microglia is necessary for normal brain development. Science 333 , 1456-1458.

Pascual, O., Achour, S. B., Rostaing, P., Triller, A., and Bessis, A. (2012).
Microglia activation triggers astrocyte-mediated modulation of excitatory neurotransmission. Proc. Natl. Acad. Sci. U.S.A. 109, E197-E205.

Pascual, O., Casper, K. B., Kubera, C., Zhang, J., Revilla-Sanchez, R., Sul, J.-Y., et al. (2005). Astrocytic purinergic signaling coordinates synaptic networks. Science 310, 113-116.

Peça, J., and Feng, G. (2012). Cellular and synaptic network defects in autism. Curr. Opin. Neurobiol. 22, 866-872.

Penzes, P., Cahill, M. E., Jones, K. A., VanLeeuwen, J.-E., and Woolfrey, K. M. (2011). Dendritic spine pathology in neuropsychiatric disorders. Nat. Neurosci. 14, 285-293.

Perry, V. H., Cunningham, C., and Holmes, C. (2007). Systemic infections and inflammation affect chronic neurodegeneration. Nat. Rev. Immunol. 7, 161-167.

Piani, D., and Fontana, A. (1994). Involvement of the cystine transport system xc- in the macrophageinduced glutamate-dependent cytotoxicity to neurons. J. Immunol. 152, 3578-3585.

Piccinin, S., Di Angelantonio, S., Piccioni, A., Volpini, R., Cristalli, G., Fredholm, B. B., et al. (2010). CX3CL1-induced modulation at CA1 synapses reveals multiple mechanisms of EPSC modulation involving adenosine receptor subtypes. J. Neuroimmunol. 224, 85-92.

Pont-Lezica, L., Béchade, C., BelarifCantaut, Y., Pascual, O., and Bessis, A. (2011). Physiological roles of microglia during development. J. Neurochem. 119, 901-908.

Ragozzino, D., Angelantonio, S. D., Trettel, F., Bertollini, C., Maggi, L., Gross, C., et al. (2006). Chemokine fractalkine/CX3CL1 negatively modulates active glutamatergic synapses in rat hippocampal neurons. J. Neurosci. 26, 10488-10498.

Rogers, J. T., Morganti, J. M., Bachstetter, A. D., Hudson, C. E., Peters, M. M., Grimmig, B. A., et al. (2011). CX3CR1 deficiency leads to impairment of hippocampal cognitive function and synaptic plasticity. J. Neurosci. 31, 16241-16250.

Roumier, A., Béchade, C., Poncer, J.-C., Smalla, K.-H., Tomasello, E., Vivier, E., et al. (2004). Impaired synaptic function in the microglial KARAP/DAP12deficient mouse. J. Neurosci. 24, 11421-11428.
Roumier, A., Pascual, O., Béchade, C., Wakselman, S., Poncer, J.-C., Réal, E., et al. (2008). Prenatal activation of microglia induces delayed impairment of glutamatergic synaptic function. PLoS ONE 3:e2595. doi: 10.1371/ journal.pone.0002595

Santello, M., Bezzi, P., and Volterra, A. (2011). TNF $\alpha$ controls glutamatergic gliotransmission in the hippocampal dentate gyrus. Neuron 69 , 988-1001.

Satoh, J.-I., Tabunoki, H., Ishida, T., Yagishita, S., Jinnai, K., Futamura, N., et al. (2011). Immunohistochemical characterization of microglia in Nasu-Hakola disease brains. Neuropathology 31 , 363-375.

Saura, J. (2007). Microglial cells in astroglial cultures: a cautionary note. J. Neuroinflammation 4:26. doi: 10.1186/1742-2094-4-26

Schafer, D. P., Lehrman, E. K., Kautzman, A. G., Koyama, R., Mardinly, A. R., Yamasaki, R., et al. (2012). Microglia sculpt postnatal neural circuits in an activity and complement-dependent manner. Neuron 74, 691-705.

Selkoe, D. J. (2002). Alzheimer's disease is a synaptic failure. Science 298, 789-791.

Shahbazian, M., Young, J., Yuva-Paylor, L., Spencer, C., Antalffy, B., Noebels, J., et al. (2002). Mice with truncated MeCP2 recapitulate many Rett syndrome features and display hyperacetylation of histone H3. Neuron 35, 243-254.

Sharma, M. K., Mansur, D. B., Reifenberger, G., Perry, A., Leonard, J. R., Aldape, K. D., et al. (2007). Distinct genetic signatures among pilocytic astrocytomas relate to their brain region origin. Cancer Res. 67, 890-900.

Stellwagen, D., and Malenka, R. C. (2006). Synaptic scaling mediated by glial TNF-alpha. Nature 440, 1054-1059.

Tang, S.-C., Arumugam, T. V., Xu, X., Cheng, A., Mughal, M. R., Jo, D. G. et al. (2007). Pivotal role for neuronal Toll-like receptors in ischemic brain injury and functional deficits. Proc. Natl. Acad. Sci. U.S.A. 104, 13798-13803.

Taylor, P. R., Martinez-Pomares, L., Stacey, M., Lin, H.-H., Brown, G. D., and Gordon, S. (2005). Macrophage receptors and immune recognition. Annu. Rev. Immunol. 23, 901-944.

Tomasello, E., Desmoulins, P. O., Chemin, K., Guia, S., Cremer, H., Ortaldo, J., et al. (2000). Combined natural killer cell 
and dendritic cell functional deficiency in KARAP/DAP12 lossof-function mutant mice. Immunity 13, 355-364.

Tremblay, M.-E., Lowery, R. L., and Majewska, A. K. (2010). Microglial interactions with synapses are modulated by visual experience. PLoS Biol. 8:e1000527. doi: 10.1371/ journal.pbio.1000527

Tremblay, M.-È., Stevens, B., Sierra, A., Wake, H., Bessis, A., and Nimmerjahn, A. (2011). The role of microglia in the healthy brain. J. Neurosci. 31, 16064-16069.

Tsuda, M., Shigemoto-Mogami, Y., Koizumi, S., Mizokoshi, A., Kohsaka, S., Salter, M. W., et al. (2003). P2X4 receptors induced in spinal microglia gate tactile allodynia after nerve injury. Nature $424,778-783$.

Ulmann, L., Hirbec, H., and Rassendren, F. (2010). P2X4 receptors mediate PGE2 release by tissue-resident macrophages and initiate inflammatory pain. $E M B O$ J. 29, 2290-2300.

Wake, H., Moorhouse, A. J., Jinno, S., Kohsaka, S., and Nabekura, J. (2009). Resting microglia directly monitor the functional state of synapses in vivo and determine the fate of ischemic terminals. J. Neurosci. 29, 3974-3980.

Watkins, L. R., Hutchinson, M. R., Ledeboer, A., Wieseler-Frank, J., Milligan, E. D., and Maier, S. F. (2007). Norman cousins lecture. Glia as the "bad guys": implications for improving clinical pain control and the clinical utility of opioids. Brain Behav. Immun. 21, 131-146.

Yrjänheikki, J., Keinänen, R., Pellikka, M., Hökfelt, T., and Koistinaho, J. (1998). Tetracyclines inhibit microglial activation and are neuroprotective in global brain ischemia. Proc. Natl. Acad. Sci. U.S.A. 95, 15769-15774.

Zamanian, J. L., Xu, L., Foo, L. C. Nouri, N., Zhou, L., Giffard, R. G., et al. (2012). Genomic analysis of reactive astrogliosis. J. Neurosci. 32, 6391-6410.

Conflict of Interest Statement: The authors declare that the research was conducted in the absence of any commercial or financial relationships that could be construed as a potential conflict of interest.

Received: 19 December 2012; accepted: 13 March 2013; published online: 28 March 2013.

Citation: Béchade C, Cantaut-Belarif $Y$ and Bessis A (2013) Microglial control of neuronal activity. Front. Cell. Neurosci. 7:32. doi: 10.3389/fncel.2013.00032

Copyright (c) 2013 Béchade, CantautBelarif and Bessis. This is an open-access article distributed under the terms of the Creative Commons Attribution License, which permits use, distribution and reproduction in other forums, provided the original authors and source are credited and subject to any copyright notices concerning any third-party graphics etc. 